\title{
THE SENSITIVITIES TO RADIATIONS AND RADIO- MIMETIC CHEMICALS OF CELLS FROM PATIENTS WITH ATAXIA TELANGIECTASIA
}

\author{
Mituo IkenaGa, ${ }^{1}$ Mitsuo Midorikawa, ${ }^{2}$ Jiro Abe, ${ }^{2}$ and Takashi Mimaki ${ }^{2}$ \\ ${ }^{1}$ Department of Fundamental Radiology, Faculty of Medicine, Osaka University, \\ Kita-ku, Osaka 530, Japan \\ ${ }^{2}$ Department of Pediatrics, Osaka University Hospital, Fukushima-ku, \\ Osaka 553, Japan
}

\begin{abstract}
Summary The lethal action of physical and chemical agents on a fibroblast strain derived from a Japanese patient with ataxia telangiectasia (AT) was measured by the cellular colony forming ability, in comparison with a British AT cell strain. Both of the AT strains showed a significantly increased sensitivity to X-rays and an antitumor agent bleomycin, as compared with normal fibroblasts. Also, the two AT strains were slightly more sensitive to methyl methanesulfonate than normal cells. The British AT strain (AT4BI) exhibited a marked sensitivity to 4-nitroquinoline 1-oxide and to mitomycin $\mathrm{C}$ compared with normal cells, whereas the Japanese AT strain (AT1OS) showed normal response to 4-nitroquinoline 1 -oxide and a reduced sensitivity to mitomycin C. Sensitivity of AT1OS cells to $N$-methyl- $N^{\prime}$-nitro- $N$-nitrosoguanidine was also normal under our experimental conditions.
\end{abstract}

\section{INTRODUCTION}

Ataxia telangiectasia (AT, sometimes called as Louis-Bar syndrome) is an autosomal recessive disorder, characterized by progressive cerebellar ataxia, telangiectasia of eye conjunctivae, and defects in immune system. Affected individuals also show elevated risk of lymphoreticular malignancy (see reviews by Arlett and Lehmann, 1978; Paterson and Smith, 1979). In 1975, Taylor et al. demonstrated that skin fibroblasts derived from AT patients were about three times more sensitive to the lethal effect of $\gamma$-rays than fibroblasts from normal donors. Since then, more than 20 AT cell strains from genetically unrelated patients have been found to be hypersensitive to X- and $\gamma$-rays (Paterson and Smith, 1979; Arlett and Harcourt, 1980). These results suggested that AT cells might have some defects in repair of DNA damage produced by ionizing radiations, analogous to xeroderma 
pigmentosum (XP) cells which are defective in repairing DNA damage induced by ultraviolet light (UV) (Cleaver, 1968).

Inoue et al. (1977) showed that extracts from several AT strains contained reduced enzyme activity that enhances the capacity of $\gamma$-irradiated DNA to act as template for a purified DNA polymerase of Escherichia coli. This indicates that AT cells may be defective in a repair exonuclease (primer activating enzyme) which converts some of the $\gamma$-ray-induced lesions into a substrate suitable for DNA polymerase action. However, rates of rejoining of $\gamma$-ray-induced single as well as double strand breaks in DNA, which are the predominant DNA lesions produced by ionizing radiations, were very similar in cells from normal donors and from AT patients (Taylor et al., 1975; Paterson and Smith, 1979). Recently, a new characteristic was found with many AT strains; the rate of DNA replication after exposure to ionizing radiations was inhibited to a lesser extent in AT cells than in normal cells (Houldsworth and Lavin, 1980; Painter and Young, 1980). The findings led these authors to speculate that the abortive DNA replication in the presence of DNA damage is the cause of hypersensitivity of AT cells to ionizing radiations. However, we still know very little about the molecular defect associated with the hypersensitivity of AT cells.

In the present report, we have made a comparative study of sensitivities of two AT cell strains, one initiated in our laboratory and the other obtained from England, to $\mathrm{X}$-rays, UV and five kinds of radiomimetic chemicals; bleomycin, methyl methanesulfonate (MMS), $N$-methyl- $N^{\prime}$-nitro- $N$-nitrosoguanidine (MNNG), mitomycin C (MMC) and 4-nitroquinoline 1-oxide (4NQO). These chemicals produce different types of DNA lesions, such as DNA strand breaks, cross-links and base adducts (Sasaki et al., 1977; Ikenaga and Takebe, 1981). Therefore, analysis of chemical sensitivities of AT cells may provide useful informations as to the nature of the defects underlying in this disease. The studies with chemical sensitivity of AT cells have been reported sporadically in the literatures (Paterson and Smith, 1979), however, comprehensive studies have not been made at least with Japanese AT cell strains.

\section{PATIENT HISTORY OF ATIOS}

A ten-year-old boy was referred to the Pediatric Neurology Clinic at Osaka University Hospital because of progressive cerebellar ataxia and repeated upper respiratory infection.

$\mathrm{He}$ was delivered by caesarean section, and his birth weight was $2,500 \mathrm{~g}$. He raised his head well at 5 months and walked alone at 14 months of age. At the age of 2 years, his parents first noticed his tottering gait. He was suffered from severe suppurative tympanitis at 4 years of age, since then he was recurrently afflicted with upper respiratory infection. Before school age, he had already developed progressive ataxic gait. 
At the age of 10 years, when he was seen in Osaka University Hospital, he could walk alone only a short distance. His height and weight were within normal range. The neurological examination revealed hyporeflexia, choreoathetosis, oculomotor apraxia and cerebellar dysarthria. Telangiectasia was seen in his bulbar conjunctivae. He showed mild mental retardation (IQ, 72). Cranial CAT examination revealed the fourth ventricular enlargement suggesting mild cerebellar atrophy. Laboratory tests disclosed a decreased serum level of IgA $(17 \mathrm{mg} / \mathrm{dl})$ and a markedly elevated level of $\alpha$-fetoprotein $(560 \mathrm{ng} / \mathrm{ml})$. Serum $\operatorname{IgE}$ and $\operatorname{IgM}$ were within normal levels.

His parents are first cousins. His elder brother is healthy.

\section{MATERIALS AND METHODS}

\section{Chemicals}

Bleomycin (Nihon Kayaku) was a clinical grade, and the stock solution (500 $\mu \mathrm{g} / \mathrm{ml}$ ) in phosphate buffered saline (PBS) was divided in many small vials and stored at $-80^{\circ} \mathrm{C}$. 4-Nitroquinoline 1-oxide (4NQO) was a gift from Dr. K. Shudo of Tokyo University. This was dissolved in ethanol $(1 \mathrm{mg} / \mathrm{ml})$ and stored at $4^{\circ} \mathrm{C}$. Mitomycin C (MMC, Kyowa Hakko, distributed by Sigma) dissolved in distilled water $(400 \mu \mathrm{g} / \mathrm{ml})$ and $N$-methyl- $N^{\prime}$-nitro- $N$-nitrosoguanidine (MNNG, Sigma) dissolved in dimethylsulfoxide $(2 \mathrm{mg} / \mathrm{ml})$ were stored in aliquots at $-80^{\circ} \mathrm{C}$. Methyl methanesulfonate (MMS) was obtained from Eastman.

All the chemical solutions were diluted immediately before treatment of the cells.

\section{Cell strains and culture conditions}

Skin fibroblasts used in the present study were two AT cell strains, AT1OS and AT4BI, and three normal cell strains, NHF3, N1KA and N9OS. For the sake of comparison, a xeroderma pigmentosum (XP) cell strain XP2OS belonging to genetic complementation group A (Takebe et al., 1977) was also used. Cultures of AT1OS, XP2OS and N9OS were initiated in our laboratory from skin specimens derived from an AT patient, an XP patient, and from a normal donor, respectively. AT4BI cells were kindly provided from Dr. Y. Fujiwara of Kobe University School of Medicine, who obtained the cells from Dr. D. G. Harnden of University of Birmingham. The normal cell strain NHF3 was supplied from Dr. Y. Fujiwara, and N1KA cells from Dr. M. Inoue of Kanazawa Medical University. Some relevant characteristics of these cell strains are listed in Table 1.

Unless otherwise specified, cells were grown in Duibecco's modified minimum essential medium (Dulbecco MEM) supplemented with $12 \%$ (v/v) fetal bovine serum (Flow Lab.), 50 units $/ \mathrm{ml}$ of penicillin G potassium, $50 \mu \mathrm{g} / \mathrm{ml}$ of streptomycin sulfate and $0.3 \mu \mathrm{g} / \mathrm{ml}$ of amphotericin B. In some experiments measuring the sensitivity 
Table 1. Characteristics of fibroblast strains used in the present study.

\begin{tabular}{lclcccl}
\hline $\begin{array}{c}\text { Cell } \\
\text { straina }\end{array}$ & $\begin{array}{c}\text { Range of } \\
\text { plating } \\
\text { efficiency } \\
(\%)\end{array}$ & $\begin{array}{c}\text { Phenotype of } \\
\text { individuals }\end{array}$ & $\begin{array}{c}\text { Age at } \\
\text { biopsy } \\
\text { (year) }\end{array}$ & Sex & $\begin{array}{c}\text { Comple- } \\
\text { mentation } \\
\text { group }\end{array}$ & Reference \\
\hline AT1OS & $2.5-10$ & Ataxia telangiectasia & 10 & $\mathrm{M}$ & $\mathrm{D}$ & This paper \\
AT4BI & $3.5-12$ & Ataxia telangiectasia & 6 & $\mathrm{M}$ & $\mathrm{C}$ & Taylor et al. (1975) \\
XP2OS & $2.5-7.5$ & Xeroderma pigmentosum & 7 & $\mathrm{~F}$ & $\mathrm{~A}$ & Takebe et al. (1977) \\
N9OS & $10-24$ & Normal & 6 & $\mathrm{~F}$ & - & This paper \\
NIKA & $4-9$ & Normal & 36 & $\mathrm{M}$ & - & Inoue et al. (1979) \\
NHF3 & $6-21$ & Normal & 3 & $\mathrm{~F}$ & - & $\begin{array}{l}\text { Fujiwara and } \\
\text { Tatsumi (1976) }\end{array}$ \\
\hline
\end{tabular}

a OS, Osaka; BI, Birmingham, England; KA, Kanazawa.

to MNNG, we used Ham's F-12 medium and a modified Eagle's MEM in which concentrations of amino acids and vitamines were doubled (Ikenaga et al., 1981).

\section{Survival assay}

Early stationary phase cells were trypsinized, and appropriate numbers of cells were seeded into 24 to 30 petri dishes $(6 \mathrm{~cm}$, Falcon or Corning) with $5 \mathrm{ml}$ each of culture medium. After 12 to $16 \mathrm{hr}$ incubation at $37^{\circ} \mathrm{C}$, the cells were treated with either one of X-rays, ultraviolet light (UV) or various chemicals. For treatment with X-rays, about three quarters of culture medium was removed from each dish, and the cells in dishes were irradiated with X-rays (Toshiba, KXC-18-5, $180 \mathrm{KVp}$, $20 \mathrm{~mA}$ ) at a dose rate of $150 \mathrm{rad} / \mathrm{min}$. After irradiation the remaining culture medium was removed from the dish, and the cells were added with fresh culture medium and incubated at $37^{\circ} \mathrm{C}$. The cells for UV irradiation were washed once with PBS and irradiated with $254 \mathrm{~nm}$ UV from germicidal lamps (Toshiba, GL-15) at fluence rates of 0.11 or $1.2 \mathrm{~J} / \mathrm{m}^{2} / \mathrm{sec}$. For chemical treatment culture medium was removed from each dish, appropriate concentration of chemical in prewarmed Eagle MEM ( $5 \mathrm{ml}$ ) without serum was added to the dish and incubated at $37^{\circ} \mathrm{C}$ for $60 \mathrm{~min}$. After the treatment the chemical solution was removed, the cells were rinsed once with PBS and added with fresh culture medium.

The cells treated with. radiations or chemicals were further incubated for 14 to 16 days to form colonies with medium renewal of twice a week. Colonies were fixed with $90 \%$ methanol, stained with Giemza and counted with a dissecting microscope. Colonies consisting of more than 50 cells were scored.

\section{RESULTS}

Figure 1a illustrates the survival response to X-rays of fibroblast cell strains derived from two normal donors and two AT patients. Colony forming abilities of both ATIOS and AT4BI cells showed greatly enhanced sensitivity to X-rays, 

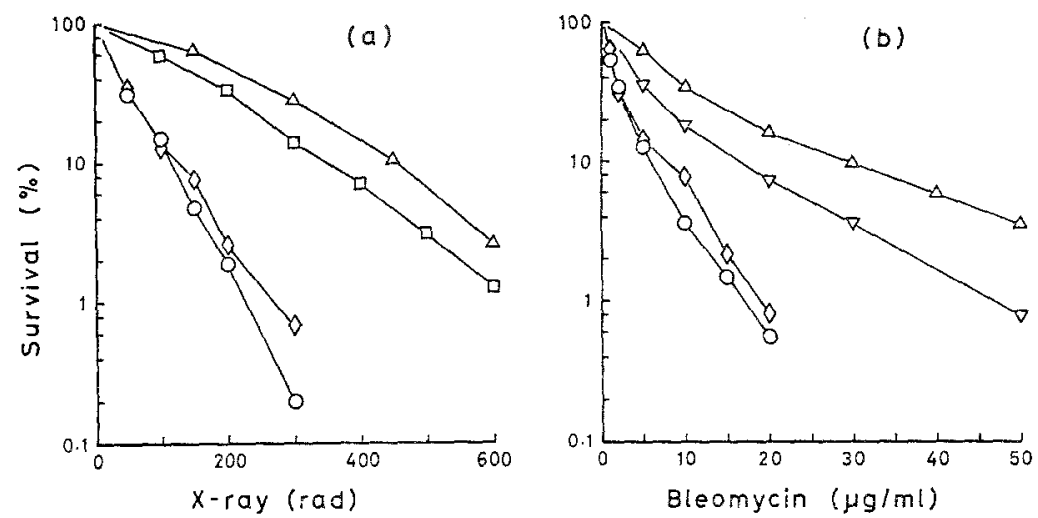

Fig. 1. Sensitivity to $X$-rays (a) and bleomycin (b) as measured by colony forming ability in skin fibroblast strains derived from normal donors and AT patients. Cells were plated on $6 \mathrm{~cm}$ cuiture dishes, allowed to attach by overnight incubation, and then irradiated with X-rays or treated with bleomycin at $37^{\circ} \mathrm{C}$ for $60 \mathrm{~min}$. Colonies were scored after 14 to 16 days incubation at $37^{\circ} \mathrm{C}$. Each point represents the average of at least 2 independent experiments for each cell strain. Normal strains, $\triangle, N 1 K A ; \square$, NHF3; $\nabla$, N9OS. AT strains, O, AT1OS; $\diamond$, AT4BI.

like all the AT strains tested to date (Arlett and Lehmann, 1978; Paterson and Smith, 1979). The $\mathrm{D}_{0}$ values (X-ray doses required to inactivate $63 \%$ of the cell population, estimated from the straight portion of the survival curves) were 150 $\mathrm{rad}$ for N1KA, $135 \mathrm{rad}$ for NHF3, $50 \mathrm{rad}$ for AT1OS and $56 \mathrm{rad}$ for AT4BI cells. This demonstrates 2 to 3 fold increase in sensitivity of these AT cell strains compared with normal cells.

Figure $1 b$ shows a variation in sensitivity to bleomycin of two normal and AT cell lines. The survival curves of the normal and AT cells exhibited biphasic response, as previously reported (Taylor et al., 1979; Lehmann and Stevens, 1979). These AT strains showed a more steeper slope compared with two normal cells, yielding an overall lower survival. The $D_{0}$ estimated from the steep component was about $2 \mu \mathrm{g} / \mathrm{ml}$ for both AT1OS and AT4BI and 6 to $10 \mu \mathrm{g} / \mathrm{ml}$ for normal cells, demonstrating that AT cells are several times more sensitive to bleomycin than normal cells in this portion of the curve.

Figure 2 shows the sensitivity of normal and AT cells to alkylating agents, MMS and MNNG. Both ATIOS and AT4BI cells were slightly more sensitive to MMS than two normal strains, N1KA and N9OS. However, there was a considerable sensitivity variation within the three normal strains; one normal strain NHF3 was about 1.5 times less sensitive to MMS than the other two normal strains. Incidentally, the two AT strains showed about 2 fold increased sensitivity to MMS compared with NHF3 cells. In order to check the effect of culture media on MNNG sensitivity of AT cells, three different subcultures of ATIOS, that is, those main- 

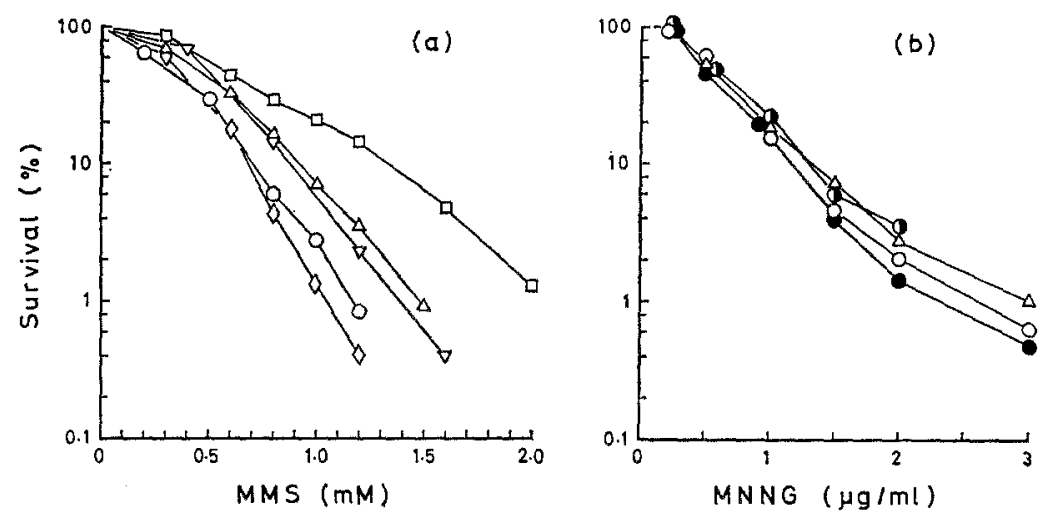

Fig. 2. Sensitivity of normal and AT fibroblasts to alkylating agents, (a) MMS and (b) MNNG. Survivals of AT1OS cells after treatment with MNNG were assayed by using three kinds of culture media, Dulbecco medium, Eagle MEM and Ham's F-12 medium, before and after the treatment. Cells were seeded and incubated overnight in these three different culture media, treated with MNNG at $37^{\circ} \mathrm{C}$ for $60 \mathrm{~min}$ in the corresponding different media without serum, and then incubated for 14 to 16 days with each of the specified culture medium. Each symbol represents the average of at least 2 independent determinations, except for those with N9OS which were determined by single experiment. $\triangle$, N1KA; $\square$, NHF3; $\nabla$, N9OS; $\diamond$, AT4BI; $O$, AT1OS assayed in Dulbecco medium; - ATIOS in Eagle medium; 1 , ATIOS in Ham's F-12 medium.

tained in Dulbecco medium, Ham's F-12 medium and in Eagle medium, were exposed to MNNG and subsequently incubated for 2 weeks in the above culture media. The results shown in Fig. $2 b$ clearly show that the sensitivity of AT1OS cells to MNNG was the same as that of normal cells, regardless of the use of different culture medium before and after the treatment.

There was a marked difference in sensitivities between the two AT strains to the carcinogen $4 \mathrm{NQO}$ and $\mathrm{MMC}$ as shown in Fig. 3. AT1OS cells showed a normal level of $4 \mathrm{NQO}$ sensitivity, whereas AT4BI cells were about 3 times more sensitive than the three normal strains. This confirmed the previous finding by Smith and Paterson (1980) that the same AT4BI cells were more sensitive to 4NQO than normal cells, in contrast to the normal response of the other AT cell line AT3BI. Although AT4BI cells were about 4 times less sensitive to 4 NQO than XP2OS strain (complementation group A) which is one of the most 4NQO sensitive human cell lines so far known, the 4NQO sensitivity of AT4BI cells was comparable to those of group $\mathrm{C} \mathrm{XP}$ cells defective in repairing 4NQO damage in DNA (Ikenaga and Takebe, 1981). AT4BI cells were slightly, but significantly, more sensitive to MMC than two normal strains, while ATIOS cells were about 2 times less sensitive compared with the normal cells (Fig. 3b). This gives about 3 fold difference in MMC sensitivity between the two AT strains. Such a remarkable resistance of 

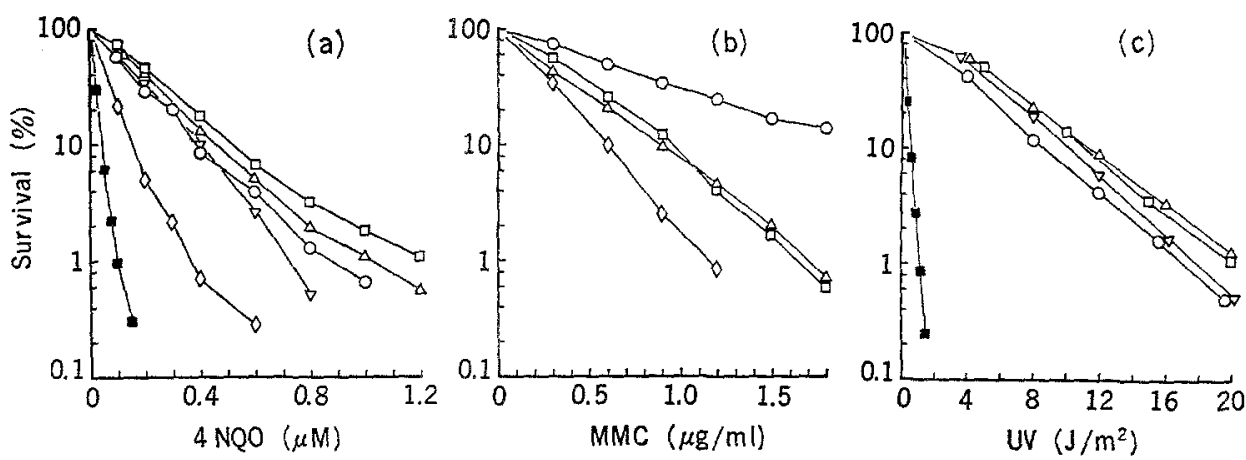

Fig. 3. Survival curves of skin fibroblast strains after treatments with (a) $4 \mathrm{NQO}$, (b) $\mathrm{MMC}$, and (c) UV. Each symbol represents the average of 2 to 6 independent experiments, except for $4 \mathrm{NQO}$ survivals of N9OS cells which were the results of single experiment. $\triangle$, N1KA; $\square$, NHF3; $\nabla$, N9OS; 0 , AT1OS; $\diamond$, AT4BI; $\mathbf{a}$, XP2OS.

AT1OS cells over normal controls has not been reported previously with any AT strains treated with various DNA damaging agents.

UV survival curve of ATIOS cells was within the normal range (Fig. 3c), as reported with various AT strains including AT4BI (Arlett and Lehmann, 1978; Paterson and Smith, 1979).

\section{DISCUSSION}

We have clinically diagnosed a 10 years old boy as being affected with AT. The results of the present study confirmed the diagnosis, since the cultured skin fibroblasts derived from the patient (AT1OS) showed an abnormally high lethal sensitivity to X-rays compared with normal cells, which is a characteristic cellular response of AT (Taylor et al., 1975). To date, more than 20 strains from genetically unrelated AT patients have been reported in the literatures that all these AT cell strains were 2.5 to 4 times more sensitive to X- or $\gamma$-rays than normal controls, when measured by their colony forming abilities (Paterson and Smith, 1979; Arlett and Harcourt, 1980). It has been also reported that AT cells are hypersensitive to the lethal effect of antitumor agent bleomycin (Taylor et al., 1979; Lehmann and Stevens, 1979). Our present results confirmed the above findings, since both ATIOS and AT4BI cells were several times as sensitive to bleomycin compared with normal cells. Bleomycin mimics the action of X-rays in the sense that it causes release of bases from DNA, and induces both single and double DNA strand breaks (Burger et al., 1981). Although the numbers of AT strains tested for their bleomycin sensitivity are limited at present, the hypersensitivity to this drug seems to be an universal phenomenon among AT strains because of the similarity between the action of bleomycin and X-rays on DNA. It would thus 
appear that reduced colony forming ability after treatment with bleomycin may provide a good cellular marker for early diagnosis of AT, as proposed for cellular $\mathrm{X}$-ray sensitivity (Cox et al., 1978).

AT1OS cells as well as AT4BI were found to be slightly more sensitive to MMS than two normal strains. There is, however, much more interstrain variability within the three normal strains used (Fig. 2a). If we compare the MMS sensitivity of these AT strains only to that of the most resistant normal cells (NHF3), we would have concluded that AT cells are abnormally sensitive to MMS. But this may be too much exaggeration. It has been reported that all the six AT strains tested exhibited a moderate level of increased sensitivity to MMS compared with seven normal strains (Hoar and Sargent, 1976). These results together with ours suggest that, in general, AT cell lines are moderately more sensitive to MMS compared with normal cells.

There is conflicting evidence with regard to the sensitivity of various AT strains to MNNG. Scudiero (1980) found that all six AT strains exhibited extreme MNNG sensitivity compared with normal cells. Similar hypersensitivity of AT cells to MNNG has been reported already by Paterson and Smith (1979), while Jaspers et al. (1982) recently observed a normal response with the same AT strains. It has been suggested that the discrepancy could be due to the use of different culture media which may affect MNNG sensitivity of AT cells (Jaspers et al., 1982). A reinvestigation of this subject under our cultural conditions revealed no apparent difference in MNNG sensitivity between normal and ATIOS cells. However, since our data were restricted in AT1OS cells, more extensive studies are desired.

In contrast to their consistent hypersensitivity of AT strains to X-rays and bleomycin, AT1OS cells showed normal response to 4NQO, though AT4BI cells known to be sensitive to the carcinogen (Smith and Paterson, 1980) exhibited 3 fold increase in $4 \mathrm{NQO}$ sensitivity under our cultural conditions. Also, AT4BI cells were found to be more sensitive to MMC than normal cells. By contrast, ATIOS cells were about 2 times less sensitive to MMC compared with normal cells (Fig. 3b). Hoar and Sargent (1976) reported that sensitivities of five different AT strains to $\mathrm{MMC}$ varied from that showing a normal response to those exhibiting 2 to 3 fold hypersensitivity. The observed marked difference in sensitivities to 4NQO and MMC between ATIOS and AT4BI cells appears to be a reflection of genetic heterogeneity of this disease, as often discussed on the basis of both clinical and cellular variabilities (Arlett and Lehmann, 1978; Paterson and Smith, 1979). At present, such heterogeneous AT cell strains are classified into at least four genetic complementation groups through A to D (Jaspers and Bootsma, 1982). It has been also known that AT4BI cells belong to group $C$ and AT1OS to group $D$. It remains to be solved whether the different responses of various AT strains to a variety of chemical agents are specific to certain genetic complementation group. On this basis, analysis of chemical sensitivity with more AT cell strains may provide better understandings of the molecular defect in this disorder. 
Acknowledgment The authors are very much indebted to Dr. Sohei Kondo of Department of Fundamental Radiology, and to Dr. Hyakuji Yabuuchi of Department of Pediatrics, Faculty of Medicine, Osaka University, for their valuable suggestions and comments. They also thank to Mr. Hideaki Ohtani for his technical assistance. This work was supported by a Grant-in-Aid for scientific research from the Japanese Ministry of Education, Science and Culture, and by a subsidy from the Ministry of Health and Welfare.

\section{REFERENCES}

Arlett, C.F. and Harcourt, S.A. 1980. Survey of radiosensitivity in a variety of human cell strains. Cancer Res. 40: 926-932.

Arlett, C.F. and Lehmann, A.R. 1978. Human disorders showing increased sensitivity to the induction of genetic damage. Anmu. Rev. Genet. 12: 95-115.

Burger, R.M., Peisach, J., and Horwitz, S.B. 1981. Mechanism of bleomycin action: In vitro studies. Life Sci. 28: 715-727.

Cleaver, J.E. 1968. Defective repair replication of DNA in xeroderma pigmentosum. Nature 218: $652-656$.

Cox, R., Hosking, G.P., and Wilson, J. 1978. Ataxia telangiectasia, evaluation of radiosensitivity in cultured skin fibroblasts as a diagnosis test. Arch. Dis. Child. 53: 386-390.

Fujiwara, Y. and Tatsumi, M. 1976. Replicative bypass repair of ultraviolet damage to DNA of mammalian cells: Caffeine sensitive and caffeine resistant mechanisms. Mutation Res. 37: 91-110.

Hoar, D.I. and Sargent, P. 1976. Chemical mutagen hypersensitivity in ataxia telangiectasia. Nature 261: 590-592.

Houldsworth, J. and Lavin, M.F. 1980. Effect of ionizing radiation on DNA synthesis in ataxia telangiectasia. Nucl. Acids Res. 8 : 3709-3720.

Ikenaga, M. and Takebe, H. 1981. Actions of 4-nitroquinoline 1-oxide on eucaryotic cells: Molecular and cellular studies. In The Nitroquinolines, Carcinogenesis, Vol. 6. Raven Press, New York. pp. 65-91.

Ikenaga, M., Inoue, M., Kozuka, T., and Sugita, T. 1981. The recovery of colony-forming ability and the rate of semi-conservative DNA synthesis in ultraviolet-irradiated Cockayne and normal human cells. Mutation Res. 91: 87-91.

Inoue, M., Yokaichi, M., Tsukada, S., Saito, I., Sasaki, K., Yamaaki, H., Annen, Y., Hirone, T., Saito, T., Ishizaki, K., and Takebe, H. 1979. DNA repair studies on xeroderma pigmentosum patients at Kanazawa Medical University. J. Kanazawa Med. Univ. 4: 65-70.

Inoue, T., Hirano, K., Yokoiyama, A., Kada, T., and Kato, H. 1977. DNA repair enzymes in ataxia telangiectasia and Bloom's syndrome fibroblast. Biochim. Biophys. Acta 479: 497-500.

Jaspers, N.G.J. and Bootsma, D. 1982. Genetic heterogeneity in ataxia telangiectasia studied by cell fusion. Proc. Natl. Acad. Sci. USA 79: 2641-2644.

Jaspers, N.G.J., de Wit, J., Regulski, M.R., and Bootsma, D. 1982. Abnormal regulation of DNA replication and increased lethality in ataxia telangiectasia cells exposed to carcinogenic agents. Cancer Res. 42: 335-341.

Lehmann, A.R. and Stevens, S. 1979. The response of ataxia telangiectasia cells to bleomycin. Nucl. Acids Res. 6: 1953-1960.

Painter, R.B. and Young, B.R. 1980. Radiosensitivity in ataxia telangiectasia: A new explanation. Proc. Natl. Acad. Sci. USA 77: 7315-7317.

Paterson, M.C. and Smith, P.J. 1979. Ataxia telangiectasia: An inherited human disorder involving hypersensitivity to ionizing radiation and related DNA-damaging chemicals. Annu. Rev. Genet. 13: 291-318. 
Sasaki, M.S., Toda, K., and Ozawa, A. 1977. Role of DNA repair in the susceptibility to chromosome breakage and cell killing in cultured human fibroblasts. In Biochemistry of Cutaneous Epidermal Differentiation. Univ. Tokyo Press, Tokyo. pp. 167-180.

Scudiero, D.A. 1980. Decreased DNA repair synthesis and defective colony forming ability of ataxia telangiectasia fibroblast cell strains treated with $N$-methyl- $N^{\prime}$-nitro- $N$-nitrosoguanidine. Cancer Res. 40: 984-990.

Smith, P.J. and Paterson, M.C. 1980. Defective DNA repair and increased lethality in ataxia telangiectasia cells exposed to 4-nitroquinoline-1-oxide. Nature 287: 747-749.

Takebe, H., Miki, Y., Kozuka, T., Furuyama, J., Tanaka, K., Sasaki, M.S., Fujiwara, Y., and Akiba, H. 1977. DNA repair characteristics and skin cancers of xeroderma pigmentosum patients in Japan. Cancer Res. 37: 490-495.

Taylor, A.M.R., Harnden, D.G., Arlett, C.F., Harcourt, S.A., Lehmann, A.R., Stevens, S., and Bridges, B.A. 1975. Ataxia telangiectasia: A human mutation with abnormal radiation sensitivity. Nature 258: 427-429.

Taylor, A.M.R., Rosney, C.M., and Campbell, J.B. 1979. Unusual sensitivity of ataxia telangiectasia cells to bleomycin. Cancer Res. 39: 1046-1050. 